\title{
PBL ou PBLs: a Customização do Mecanismo de Aprendizagem Baseada em Problemas na Educação Contábil
}

Fábio Frezatti*1 e Daiana Bragueto Martins²

${ }^{1}$ Departamento de Contabilidade e Atuária, ${ }^{2}$ Programa de Pós-graduação em Controladoria e Contabilidade Faculdade de Economia, Administração e Contabilidade da Universidade de São Paulo

* Autor para correspondência: frezatti@usp.br

\section{RESUMO}

O objetivo desta pesquisa é tratar da questão da customização de técnicas alternativas do Problem-based Learning (PBL) nos cursos de graduação e de especialização. A análise volta-se para experiências docentes em que as vertentes Problem-based Learning (One-day One-problem), Case-based Learning e Project-based Learning se apresentam como elementos adicionais para o aperfeiçoamento do ambiente educacional da área de negócios, particularmente, da contabilidade, respeitando o conhecimento previamente adquirido pelos alunos e proporcionando a integração com o seu contexto profissional. Nesse sentido, o artigo contribui para o entendimento dos vários tipos de mecanismos relacionados à utilização de problemas no ensino da contabilidade. A investigação empírica aconteceu a partir da utilização da abordagem action research em meio a casos constituídos por turmas de graduação de forma a evidenciar experiências vivenciadas em disciplinas de controle gerencial ofertadas tanto no curso de graduação em Ciências Contábeis da FEA-USP como em cursos de pós-graduação lato sensu (Master in Business Administration - MBA) no cenário brasileiro. Entre os resultados da pesquisa destacam-se os seguintes fatos: a literatura não é convergente em relação a aspectos estruturais, e a aplicação do PBL não deve ser feita de uma única maneira, mas sim com formatos diferentes de abordagem, observando a maturidade dos alunos, a complexidade dos elementos considerados, o tempo disponível para a disciplina e o objetivo em si (discussão e/ou implementação da solução).

Palavras-chave: Problem-based Learning, Case-based Learning, Project-based Learning, Educação Contábil

\begin{abstract}
The aim of this research is to address the issue of customization alternatives Problem-based Learning (PBL) techniques in undergraduate and lato sensu postgraduate courses. The analysis of the teaching experiences in the Problem-based Learning (One-day One-problem), in the Case-based Learning and in the Project-based Learning are presented as additional elements to improve the educational environment of business courses, particularly accounting, respecting the students' previous knowledge and providing integration with their professional context. In this direction the article contributes to the understanding of the various types of mechanisms geared to the use of problems in accounting education. Empirical research supported by action research methodology happened by classes of undergraduate students in order to highlight life experiences in management control courses offered both in undergraduate degree in Accounting, at FEA USP, as in lato sensu postgraduate courses (Master in Business Administration - MBA) in the Brazilian scene. Among the research results it is emphasized that the literature is not convergent with respect to structural aspects and the PBL's application should not be done in a unique way, but with different formats of the approach, observing the students' maturity, the complexity of the elements, the time available for the course and the goal itself (discussion and/or implementation of the solution).
\end{abstract}

Keywords: Problem-based Learning, Case-based Learning, Project-based Learning, Accounting Education.

\section{Introdução}

A promoção de um ambiente educacional cooperativo tem sido o foco de discussões acadêmicas a respeito das experiências compartilhadas entre professores e alunos em que ambos participam do processo de construção do conhecimento e do desenvolvimento de habilidades e de atitudes (DECKER \& BOUHUIJS, 2009). Tal perspectiva corrobora, por sua vez, a aproximação entre a academia e o mercado, por meio da prática empresarial, possibilitando maior interface entre esta e a teoria apresentada no decorrer da formação 
universitária (ENEMARK \& KJAERSDAM, 2009). A utilização da abordagem PBL traz a prática para dentro da sala de aula; entretanto, o que deveria ser levado em conta no design do projeto? Esse questionamento se apresenta como um problema frequente, embora nem sempre tratado de forma estruturada pela literatura construtivista que busca aproximar a teoria da prática e o mercado de trabalho da academia (SAVERY, 2006).

Woods (2014) identifica mais de trinta ambientes de aprendizagem diferentes nos quais a metodologia Problem-based Learning (PBL) é aplicável. Tal conjunto constitui-se em uma família de mecanismos que são utilizados no processo educacional integrativo de active learning baseado em problemas. Trata-se de uma metodologia em que tudo é construído a partir do problema. $\mathrm{O}$ problema é seu início, e toda a construção da solução estrutura-se a partir desse elemento. O ambiente de aprendizagem é a forma como se operacionaliza o PBL em sala de aula, e a complexidade do problema a ser tratado tem impacto sobre as opções. Dessa maneira, o presente trabalho analisa as aplicações com perfil Problem-based Learning (One-day One-problem), Case-based Learning e Project-based Learning.

Existem consequências das escolhas, inclusive sobre as habilidades e as atitudes que se deseja incentivar. Este artigo tem por objetivo analisar comparativamente as abordagens da metodologia ativa de aprendizagem derivadas do PBL, por meio de mecanismos centrados nos alunos, baseando-se em casos e em projetos observados em disciplinas de controle gerencial ofertadas tanto no curso de graduação em Ciências Contábeis como em cursos de pós-graduação lato sensu (MBA) no cenário brasileiro. Visa, também, a descrever as principais características, as diferenças, as semelhanças, os benefícios, os requisitos necessários no ambiente institucional e a estrutura educacional proposta em cada modalidade, tendo em vista que, no panorama nacional, o currículo dos cursos de ciências contábeis, bem como o ensino de disciplinas de controle gerencial, são norteados por metodologias tradicionais.

\section{Conceitos e Aplicações: Problem-based Learning, Case-based Learning e Project- -based Learning}

Quando um problema é utilizado para sintetizar o conhecimento prévio aprendido e para desenvolver competências como o pensamento crítico, o trabalho em equipe, a comunicação, a resolução de problemas, as habilidades de pesquisa, pode-se utilizar como abordagem de ensino o Problem-based Learning (One-day One-problem), Case-based Learning ou Project-based Learning. Convém destacar que estes modelos servem como pontos de referência para a aprendizagem por meio de experiências do mundo real para estudantes de graduação e de pós-graduação.

$\mathrm{Na}$ abordagem do Case-based Learning, o aluno traz para a sala de aula um problema vivenciado na organização em que trabalha, trabalhou ou realiza estágio. A taxonomia do PBL descrita por Barrows (1986) apresenta contextos em que a abordagem do Case-based Learning é aplicada no processo de ensino aprendizagem, por meio de seis modelos: (i) estudo de caso baseado em aulas expositivas; (ii) aulas expositivas baseadas em estudo de caso; (iii) metodologia de estudo de casos; (iv) metodologia de estudo de casos modificados; (v) metodologia baseada em problema; e (vi) metodologia baseada em problema reiterativo. Observa-se que a complexidade da utilização do caso no processo de ensino aprendizagem parte de um contexto em que o caso é inserido como um material didático em um cenário tradicional (modelos i a iv) para uma abordagem de ensino que promove maior autonomia da aprendizagem, maior desenvolvimento do processo de raciocínio diagnóstico, até chegar a uma investigação completa e complexa, como ocorre em situações reais de atuação profissional (modelos v e vi), que serão objeto da análise deste trabalho. Nota-se que os casos auxiliam os alunos a compreenderem os elementos importantes de uma determinada situação, de modo a prepará-los para atuarem em 
circunstâncias semelhantes no futuro no seu respectivo contexto.

O Problem-based Learning originou-se na década de 1960 e é caracterizado por ser uma abordagem de ensino que ocorre em pequenos grupos que desenvolvem habilidades sociais de aprendizagem por meio de discussões, resolução de problema e estudo com os pares (HMELO-SILVER, 2004). Para Savery (2006), o Problem-based Learning é uma abordagem curricular centrada no aluno que o capacita a realizar pesquisas, integrar teoria e prática e aplicar conhecimentos e habilidades para o desenvolvimento de uma solução viável para um problema definido. Destaca-se que é fundamental para o desenvolvimento da metodologia que o problema tenha vínculo com o real, seja complexo, mal estruturado, interdisciplinar e permita a investigação. Segundo essa perspectiva, trabalha-se com um problema por dia (PBL - One-day One-problem), principalmente com turmas de alunos de graduação em estágios iniciais do curso, visando, além do conhecimento, a prepará-los para a habilidade de solução de problemas. O professor assume o papel de tutor que orienta o processo de aprendizagem. Os alunos, por sua vez, devem ser o centro de tal ação continuada e os responsáveis por ela. As avaliações medem o progresso da turma em direção às metas de aprendizagem, e a autoavaliação e a avaliação pelos pares devem ocorrer ao final de cada problema ou ao final de cada unidade curricular.

O Project-based Learning contempla problemas trabalhados por meio de projetos, os quais são estudados desde 1921 por Kilpatrick. Nessa abordagem, os trabalhos são sempre realizados em equipes, os processos de aprendizagem são orientados para seguir os procedimentos corretos e espera-se que seja desenvolvido um produto final. Observa-se que, ao trabalhar com um projeto, os alunos estão suscetíveis a encontrar vários problemas que promovem momentos de ensino. Os professores assumem o papel de gestores das equipes e fornecem orientação especializada, feedback e sugestões de formas diferentes de desenvolver o produto final. O ensino é fornecido conforme a necessidade do aluno e dentro do contexto do projeto (SAVERY, 2006). O Project-based Learning dispõe de muitos elementos que são comuns no Problem-based Learning (One-day One-problem), embora aquele apresente uma ênfase maior na realização de um produto, na multidisciplinaridade, na reflexividade e na pedagogia centrada no aluno. Este traz um assunto único e mais curto, fazendo com que o ensino ocorra por meio de etapas específicas, mediante a utilização de cenários e de casos que são menos relacionados com a vida real. Ambos, por sua vez, promovem a aprendizagem ativa e o ensino do século XXI (LARMER, 2014). A Tabela 1 apresenta as semelhanças e as diferenças entre as três abordagens.

\section{Estudos no Brasil}

A abordagem do PBL expandiu-se pelas diversas áreas de conhecimento e pode ser observada em diferentes contextos desde o ensino infantil até o universitário e o profissional (SAVERY, 2006). No ensino superior, abrange tanto os cursos de graduação como os de pós-graduação e os Master in Business Administration (MBA). No tocante à educação contábil, é possível encontrar evidências do PBL a partir da década de 1990, ainda que no Brasil as pesquisas que relatam as experiências com essa abordagem entrem em cena no século XXI. Nos cursos de graduação, a abordagem baseada em problemas pode ser desenvolvida tanto no início do curso quanto no meio e ao final dele. Dependendo das opções estruturais do projeto político-pedagógico da instituição, há a possibilidade de o PBL ser direcionado e desenhado de formas diferentes, no sentido de proporcionar uma adequada aprendizagem ao aluno, conforme destaca a Tabela 2.

Como se percebe, há o interesse em desenvolver as atividades derivadas da abordagem de active learning em negócios como um todo e, em particular, na contabilidade. No ambiente nacional de ensino em contabilidade, não existe consistência entre os estudos, tanto ao rigor relacionado a uma dada vertente quanto à perceptibilidade de sua localização no âmbito do PBL. 


\begin{tabular}{|c|c|c|c|}
\hline \multirow[b]{2}{*}{ SEMELHANÇAS } & \multicolumn{3}{|c|}{ DIFERENÇAS } \\
\hline & $\begin{array}{l}\text { PROBLEM-BASED } \\
\text { LEARNING (One-day } \\
\text { One-problem) }\end{array}$ & $\begin{array}{l}\text { PROJECT-BASED } \\
\text { LEARNING }\end{array}$ & $\begin{array}{l}\text { CASE-BASED } \\
\text { LEARNING }\end{array}$ \\
\hline $\begin{array}{l}\text { - Envolvem os alunos } \\
\text { em problemas reais. } \\
\text { - O aluno é o centro } \\
\text { do processo de ensino } \\
\text { aprendizagem. }\end{array}$ & $\begin{array}{l}\text { - Desfecho: apresenta, } \\
\text { por meio de relatório } \\
\text { ou apresentação oral, } \\
\text { uma proposta de solu- } \\
\text { ção para o problema } \\
\text { de baixa complexidade } \\
\text { conceitual e teórica. }\end{array}$ & $\begin{array}{l}\text { - Desfecho: apresen- } \\
\text { ta relatório, tratando } \\
\text { problema de grande } \\
\text { complexidade, demanda } \\
\text { consenso no grupo e } \\
\text { pode ser finalizado com } \\
\text { criação de um produ- } \\
\text { to ou implementação } \\
\text { de algum mecanismo } \\
\text { complexo. }\end{array}$ & $\begin{array}{l}\text { - Desfecho: apresenta, } \\
\text { por meio de relatório ou } \\
\text { apresentação oral, uma } \\
\text { proposta de solução para } \\
\text { o problema de grande } \\
\text { complexidade onde os } \\
\text { alunos têm autonomia } \\
\text { para identificar neces- } \\
\text { sidades conceituais e } \\
\text { teóricas. }\end{array}$ \\
\hline $\begin{array}{l}\text { - Desenvolvem as } \\
\text { competências do século } \\
\text { XXI. } \\
\text { - Proporcionam apli- } \\
\text { cações autênticas de } \\
\text { conteúdos e habilidades. }\end{array}$ & $\begin{array}{l}\text { - Atividade principal: o } \\
\text { inquérito de situações } \\
\text { problemáticas; normal- } \\
\text { mente o problema é } \\
\text { definido pelo professor. }\end{array}$ & $\begin{array}{l}\text { - Atividade principal: } \\
\text { desenvolver soluções } \\
\text { baseadas em evidên- } \\
\text { cias para um problema } \\
\text { existente em alguma } \\
\text { organização ao alcance } \\
\text { dos alunos. }\end{array}$ & $\begin{array}{l}\text { - Atividade principal: } \\
\text { desenvolver soluções } \\
\text { baseadas em evidên- } \\
\text { cias para um problema } \\
\text { existente em alguma } \\
\text { organização, o qual será } \\
\text { definido pelos alunos e } \\
\text { estará ao alcance deles. }\end{array}$ \\
\hline $\begin{array}{l}\text { - Incentivam a autono- } \\
\text { mia e a pesquisa. } \\
\text { - Trabalho em pequenos } \\
\text { grupos. }\end{array}$ & $\begin{array}{l}\text { - Duração: uma ou } \\
\text { duas aulas. }\end{array}$ & $\begin{array}{l}\text { - Duração: semanas ou } \\
\text { meses. }\end{array}$ & $\begin{array}{l}\text { - Duração: semanas ou } \\
\text { meses. }\end{array}$ \\
\hline $\begin{array}{l}\text { - Simulação de uma } \\
\text { situação profissional. } \\
\text { - Processamento de } \\
\text { múltiplas fontes de infor- } \\
\text { mação. }\end{array}$ & $\begin{array}{l}\text { - Princípio: aprendiza- } \\
\text { gem interativa. }\end{array}$ & $\begin{array}{l}\text { - Princípio: gerencia- } \\
\text { mento de projetos, } \\
\text { considerando até mesmo } \\
\text { a perspectiva de imple- } \\
\text { mentação. }\end{array}$ & $\begin{array}{l}\text { - Princípio: aprendiza- } \\
\text { gem interativa. A imple- } \\
\text { mentação não necessa- } \\
\text { riamente é apresentada } \\
\text { como etapa. }\end{array}$ \\
\hline $\begin{array}{l}\text { - O professor é o faci- } \\
\text { litador no processo de } \\
\text { ensino aprendizagem. } \\
\text { - A avaliação é formati- } \\
\text { va e baseada no desem- } \\
\text { penho (autoavaliação e } \\
\text { avaliação pelos pares). }\end{array}$ & $\begin{array}{l}\text { - Aprendizagem autodi- } \\
\text { rigida: plenamente cen- } \\
\text { trada no aluno em um } \\
\text { ambiente pré-definido. }\end{array}$ & $\begin{array}{l}\text { - Aprendizagem auto- } \\
\text { dirigida: aprendizagem } \\
\text { centrada no aluno } \\
\text { dentro de um projeto } \\
\text { definido. }\end{array}$ & $\begin{array}{l}\text { - Aprendizagem autodiri- } \\
\text { gida: plenamente cen- } \\
\text { trada no aluno em um } \\
\text { ambiente definido pelo } \\
\text { perfil do grupo. }\end{array}$ \\
\hline
\end{tabular}

Tabela 1 - Semelhanças e diferenças: Problem-based Learning e Project-based Learning. Fonte: Adaptado de WIEK et al. (2014) e LARMER (2014).

\section{Metodologia}

A investigação empírica acontece por meio da utilização da abordagem action research (COUGHLAN \& COUCHLAN, 2002), a partir do acompanhamento de turmas de alunos, de modo a destacar experiências vivenciadas em disciplinas de controle gerencial ofertadas tanto no curso de graduação em
Ciências Contábeis como em cursos de pós-graduação lato sensu (MBA) no cenário brasileiro. A técnica de pesquisa utilizada envolveu uma abordagem descritiva das aulas de PBL em duas edições de uma disciplina que trata do controle gerencial. Além disso, buscou-se entender o ponto de vista das pessoas que estavam sendo estudadas, com intuito de se preser- 


\begin{tabular}{|c|c|}
\hline AUTORES & \multicolumn{1}{c|}{ OBJETIVO DA PESQUISA } \\
\hline $\begin{array}{c}\text { Rodrigues \& Araújo } \\
\text { (2007) }\end{array}$ & $\begin{array}{l}\text { Investigaram a aplicabilidade do méto- } \\
\text { do PBL nas disciplinas de Contabilida- } \\
\text { de Geral e de Contabilidade Gerencial } \\
\text { do curso de Administração de uma ins- } \\
\text { tituição de ensino superior particular do } \\
\text { Estado de São Paulo. }\end{array}$ \\
\hline Siqueira et al. (2009) & $\begin{array}{l}\text { Coletaram e investigaram a percepção } \\
\text { de quinze alunos voluntários da disci- } \\
\text { plina de Contabilidade de Custos II de } \\
\text { uma instituição de ensino superior pú- } \\
\text { blica sobre a aplicabilidade no método } \\
\text { PBL na área contábil. }\end{array}$ \\
\hline Araújo et al. (2010) & $\begin{array}{l}\text { Relataram a aplicação do PBL como } \\
\text { metodologia de ensino no curso de es- } \\
\text { pecialização (lato sensu) em Controlado- } \\
\text { ria e Finanças em uma instituição de en- } \\
\text { sino superior do Estado de São Paulo. }\end{array}$ \\
\hline
\end{tabular}

Benjamin Junior \&

Casa Nova (2012)

Frezatti \& Silva (2014)

Frezatti et al. (2016)

Sockalingam et al. (2014)

Martins et al. (2015)
Realizaram um estudo quase-experimental com estudantes de graduação da disciplina de Contabilidade de Custos II que se revezam nas metodologias de ensino tradicional e PBL.

Discutiram as estratégias para manter o interesse dos estudantes perante a disciplina de Controle Gerencial.

As dificuldades existentes no processo avaliativo na disciplina ministrada a partir da ótica do PBL.

Análise comparativa entre dois modelos de PBL.

Relataram a operacionalização do método PBL em uma disciplina de Contabilidade Gerencial no curso de Ciências Contábeis de uma instituição de ensino superior brasileira.

\section{OPERACIONALIZAÇÃO DO PBL}

As etapas propostas por Sakai e Lima (1996).

O método dos sete passos apresentados por Komatsu (2003).

Implantaram por meio de estudo de caso de controladoria, seguindo as etapas propostas na pesquisa de Barrows (1996).

Utilizaram casos de ensino. Não há evidências no decorrer do artigo dos passos utilizados para operacionalizar o processo de resolução do caso de ensino.

Utilizaram os princípios básicos do Case-based Learning tendo como base teórica a experiência apresentada por Araújo e Arantes (2009) desenvolvida na Escola de Artes, Ciências e Humanidades (EACH) da USP.

A experiência brasileira do modelo de Case-based Learning na disciplina de Controle Gerencial e outro em Cingapura cujo modelo é o Problem-based Learning (One-day One-problem) aplicado na Republic Polytechnic.

A abordagem da aprendizagem centrada em projetos e baseadas em problemas (Project and Problem-based Learning), que está alinhada ao modelo de Araújo e Arantes (2009).

Tabela 2 - Experiências com o PBL no ensino de controle gerencial no cenário nacional.

varem as múltiplas realidades e os diferentes pontos de vista sobre o fenômeno analisado (STAKE, 1995).

No primeiro caso, a pesquisa de campo ocorreu no primeiro semestre de 2014 em ambiente real de sala de aula na disciplina de controle gerencial ofertada para o curso de Ciências Contábeis, que utiliza o método de ensino Case-based Learning. A coleta de dados para o segundo caso aconteceu em ambiente real de sala de aula na disciplina de controle gerencial ofertada para o curso de MBA de 
uma instituição privada que também utiliza como método instrucional o Case-based Learning. Os estudos foram realizados com intuito de apresentar uma análise comparativa das duas abordagens de ensino construtivista no ensino de contabilidade gerencial e, assim, constatar as condições reais de implantação do método $\mathrm{PBL}$, suas vantagens e desvantagens, o perfil do projeto pedagógico, dos alunos e dos professores destas duas disciplinas.

Assim, a trajetória metodológica aplicada para o desenvolvimento destes estudos de campo é qualitativa e interpretativista. Paralelamente, convém assinalar que os instrumentos empregados para a coleta de dados são os documentos institucionais e didáticos utilizados para o desenvolvimento das disciplinas e os relatos da experiência vivenciada pelos integrantes do processo educacional. Como resultado de tal empreitada, objetiva-se propor um guia baseado nas experiências realizadas no Brasil para as iniciativas semelhantes em disciplinas de controle gerencial em outros cursos e em outras universidades, tanto no Brasil quanto em outros países.

\section{O Projeto Pedagógico, o Aluno e o Professor}

\section{Ensino de Contabilidade com Case-based Lear- ning na Graduação}

A disciplina na área de controle gerencial ofertada ao curso de Ciências Contábeis da FEA-USP promove o ensino por meio da abordagem educacional do Case-based Learning. A matriz curricular do curso é tradicional, sendo que esta disciplina optativa foi criada em 2011 exclusivamente para proporcionar aos futuros profissionais da área contábil uma experiência acadêmica mais próxima da realidade apresentada pelo mercado de trabalho e, assim, aproximar, por meio do PBL, os alunos da prática profissional e da pesquisa e promover o desenvolvimento de competências passíveis de serem aplicadas no decorrer de sua carreira profissional com base na diretriz learn to learn. É importante destacar que, para a grande maioria dos graduandos que já cursaram a disciplina, esta foi a primeira experiência com o PBL. Eles assumem uma postura ativa e trabalham em grupos desde a primeira aula. O professor assume o papel de facilitador. Atua de forma a auxiliar os grupos a atingir seus objetivos.

As etapas do processo de operacionalização do método realizadas no ambiente educacional estão alicerçadas na proposta apresentada por Araújo e Arantes (2009): a disciplina possui um tema geral que é subdividido em sete subtemas; os alunos escolhem um problema de controle gerencial emergente nas empresas em que trabalham, o qual deverá ser relativo a um dos subtemas apresentados; a disciplina suporta turmas com até cinquenta alunos que se reúnem em grupos de cinco estudantes; os grupos de trabalho atuam juntos durante todo o semestre na solução de um problema por eles escolhido. O desenvolvimento do trabalho em grupo acontece da seguinte maneira: após selecionarem o problema, elencam hipóteses que podem explicar a causa desse problema; ao mesmo tempo, utilizam o conhecimento prévio, as suas próprias experiências profissionais, as discussões com o docente e as pesquisas bibliográficas na busca por respostas para solucionar o problema investigado; apresentam os seus resultados por meio de dois relatórios científicos, um parcial e outro final, em que apontam as reflexões teóricas e as análises sobre o problema estudado; e exibem, por meio de filme, o produto final do projeto, o qual é socializado na última aula.

As aulas estão divididas da seguinte maneira: as primeiras reuniões contêm aulas expositivas, pois se faz necessário explicar para os alunos o que é e como funciona a metodologia do PBL, as competências a serem desenvolvidas nesta abordagem educacional, os conteúdos a serem abordados em cada tema e as questões envolvendo metodologia da pesquisa científica. Os estudantes reúnem-se em grupos para discutir e selecionar os problemas; o líder do grupo é o aluno cujo problema está integrado a sua realidade profissional. Nessa etapa, os grupos contextualizam o problema; geram as hipóteses; dividem as tarefas e começam a trabalhar em busca de um produto final. Na quinta aula, ocorre a legitimação dos problemas e dos grupos; cada grupo apresenta para a turma os problemas; estes 
são discutidos quanto à relevância para o tema da disciplina e a sua viabilidade. A partir de tal aula, iniciam-se as sessões tutorais voltadas aos pequenos grupos que têm por objetivo buscar coletivamente a resolução dos problemas, possibilitar a troca de experiência entre os alunos e seus pares e entre os alunos e o docente. As socializações dos resultados parciais e finais visam a compartilhar, discutir e debater os resultados obtidos pelos grupos menores. No meio do semestre, há a prova de conhecimento sobre o PBL e sobre os conteúdos abordados em seus projetos. Na última aula, os alunos realizam a autoavaliação, a avaliação pelos pares e a avaliação do método.

A principal desvantagem da implantação do método PBL, com base na percepção dos alunos, está atrelada à resistência deles em assumir uma postura ativa em sala de aula, pois estão acomodados com aulas expositivas e tendem a rejeitar inovações. Como para muitos não é comum o processo de

\section{FRAGMENTOS}

Fragmento 1. Aluno 6

Fragmento 2. Aluno 4

Fragmento 3. Aluno 5

Fragmento 4. Aluno 6

Fragmento 5. Aluno 15

Fragmento 6. Aluno 10

Fragmento 7. Aluno 6

Fragmento 8. Aluno 3

Fragmento 9. Aluno 13

Fragmento 10. Aluno 3

Fragmento 11. Aluno 10

Fragmento 12. Aluno 7

Fragmento 13. Aluno 5

\section{PERCEPÇÃO DOS DISGENTES}

Inovadora, porém prefiro a metodologia tradicional, onde aprendo mais. [...] Nãa gostei. Prefiro métodos tradicionais.

Menos sessões tutoriais, mais aulas expositivas.

Deve-se ter maior controle do que cada aluno está fazendo dentro dos grupos.

Acredito que um melhor controle sobre os componentes de cada grupo e mais atividades individuais.

Cursaria [outra disciplina com PBL], pois o PBL nos tira do conforto de ficar apenas olhando o professor apresentar, e faz com que a gente corra atrás das soluções durante o semestre.

O fato de nós, alunos, termos uma liberdade de ação, fez com que eu pesquisasse e aprendesse conteúdos muito interessantes e com certeza a fixação dos conteúdos foi maior do que em disciplinas convencionais.

O fato de não haver aulas expositivas me faz pesquisar muito por conta, assim aprendo mais conteúdos.

[...]foi muito válido o aprendizado do trabalho em grupo, houve muita cooperação e discussão.

[...]pensar em grupo agrega muito mais conhecimento e instiga novas hipóteses a serem pensadas.

Houve integração com outras disciplinas, principalmente com a de contabilidade de custos e orçamento e planejamento estratégico...

Essa metodologia se assemelha muito com o dia a dia empresarial.

No mundo profissional quando, por exemplo, uma legislação será alterada, algo semelhante ao PBL pode ser utilizado.

O desenvolvimento do curso nos permitiu alinhar a teoria a algumas questões práticas.

Tabela 3 - Percepção dos alunos sobre o PBL. 
construção do conhecimento, completam-se, assim, os resultados apresentados na pesquisa de Wood (2003) e Martins e Espejo (2015), tal como se pode perceber nos fragmentos 1 e 2 da Tabela 3 .

Conforme apresentado na pesquisa de Escrivão Filho e Ribeiro (2008), foi possível observar, por meio dos fragmentos 3 e 4 , que para alguns alunos é difícil o desenvolvimento de uma aprendizagem colaborativa. Entre as vantagens proporcionadas pelo PBL no processo de ensino e aprendizagem que constam da pesquisa realizada por Wood (2003), os elementos a seguir foram evidenciados pelos alunos: o PBL como uma abordagem centrada no aluno (fragmento 5); o PBL proporciona uma aprendizagem mais profunda (fragmentos 6 e 7); o PBL incrementa a percepção do benefício de trabalhar em grupo (fragmentos 8 e 9); o PBL desenvolve competências que serão utilizadas na prática profissional (fragmentos 11 e 12); o PBL promove a interdisciplinaridade (fragmento 10). Observa-se que uma das principais vantagens do PBL é aproximar a teoria ensinada no universo acadêmico das práticas profissionais (SAVERY, 2006; ENEMARK \& KJAERSDAM, 2009).

Assim, ao utilizar o PBL, esta disciplina buscou aproximar o futuro contador das funções práticas exercidas na área de controle gerencial por meio de problemas oriundos das empresas brasileiras. Diversos alunos identificaram em seus relatos essa integração entre teoria, pesquisa científica e prática profissional, conforme os fragmentos 11 a 13.

Percebe-se que, em uma disciplina não tradicional, com muitas atividades executadas pelos alunos, avaliação pelos pares, avaliação de habilidades e atitudes, ao mesmo tempo em que ela é recebida de forma favorável pela questão da praticidade, também provoca dúvidas quanto ao seu andamento. Mais especificamente, na perspectiva dos graduandos, ao buscarem referencial já estudado ao longo do curso para resolverem o problema proposto, eles tanto tecem elogios às questões práticas quanto também fazem críticas à falta de mais aulas expositivas. Do lado do docente, por sua vez, tanto no que se refere à preparação como ao gerenciamento da classe, o tempo dedicado a tais atividades é maior do que em uma disciplina tradicional. Pelo simples fato de não saber quais dificuldades surgirão na sala de aula em decorrência das discussões, a carga de trabalho do professor torna-se maior nessa comparação, pois se faz necessário a ele buscar literatura e envolver-se na discussão produzida pelos alunos ou mesmo nas crises que podem aparecer no transcorrer do processo.

Uma característica relevante da disciplina diz respeito ao fato de que ela é oferecida aos alunos que se encontram na parte avançada do curso, ou seja, nos três últimos semestres, momento em que muitos dos estudantes já se encontram inseridos no mercado de trabalho. Dessa maneira, a flexibilidade de escolha do problema é considerada adequada para o momento do curso. Caso fosse disponibilizada para os ingressantes, focando tópicos das disciplinas introdutórias, os problemas deveriam ser definidos pelos professores.

\section{Ensino de contabilidade com Case-based Learning no $M B A$}

A abordagem conceitual é análoga à descrita no item referente ao curso de graduação, e as diferenciações encontram-se especificadas a seguir.

A aplicação do referido método no curso de MBA tem por motivação a aplicabilidade dos conceitos, bem como a troca de experiências entre os participantes, algo muito relevante nesse tipo de curso. Leva em conta as diferenciações importantes em relação a seu emprego no curso de graduação: (i) os alunos têm mais experiência profissional; (ii) os conceitos e teorias foram obtidos algum tempo atrás e podem ser resgatados, não sendo uma "novidade" para os alunos; e (iii) os alunos vivenciaram problemas profissionais com maior intensidade do que os graduandos, tendo a oportunidade não apenas de perceber o problema, mas apresentar a devida ponderação de sua importância. Essa modalidade de disciplina existe desde 2010, sendo oferecida atualmente.

As turmas são compostas por entre 20 e 25 alunos, com formação relativamente homogênea, ou seja, de contabilidade, administração, economia e engenharia, predominantemente. Diferentemente dos alunos de graduação, a faixa etária está situada entre 25 e 
40 anos e atuam em empresas de diversas configurações, setores e portes, o que acaba proporcionando grande riqueza aos debates e melhor entendimento do fato de que não existe apenas uma única resposta correta para um determinado problema.

Definidos os subtemas, os problemas são identificados pelos alunos que se agrupam de forma estruturada para que cada grupo tenha em seu conjunto vários perfis. Essa lógica possibilita olhar o mesmo problema sob diferentes perspectivas no que diz respeito a experiências, tipos de setores etc. Na graduação, esse não é o critério básico, devido ao fato de que a pouca experiência dos participantes faz com que alguém com um pouco mais de vivência direcione o grupo, o que, em geral, ocorre em menor escala num grupo de MBA.

Por dispor de menos tempo do que o curso voltado aos alunos de graduação (seis sessões de quatro horas versus quinze sessões de cem minutos), prioriza-se aquilo que é mais relevante. Relativamente, mais tempo extra-aula deve ser dedicado ao desenvolvimento dos trabalhos, e a articulação dos grupos se torna mais crítica, pois não existe $o$ monitoramento feito pelo professor durante o desenvolvimento das aulas. Tal acompanhamento é realizado tão somente na disciplina ofertada aos alunos de graduação. Por outro lado, assim como nesta, o curso de MBA também desenvolveu o processo de ensino-aprendizagem com foco no aluno, promoveu uma aprendizagem mais profunda e com ênfase na interdisciplinaridade, ao mesmo tempo em que foram desenvolvidas competências que são aplicadas na prática profissional (WOOD, 2003). As avaliações feitas são padronizadas pela instituição, não existindo feedback formalizado dos alunos quanto à sua reação perante a metodologia. Essa reação é captada como um todo, em termos de ser ou não adequada ao curso, bem como por meio do feedback informal com alguns alunos ao final do curso.

\section{Considerações Finais}

Este artigo discute as aplicações de uma abordagem que se inclui no âmbito do active learning, o PBL, sugerindo que seja estudado o melhor formato para sua implantação (PBL
One-day One-problem, Case-based Learning ou Project-based learning), considerando as características do ambiente de aprendizagem que deve levar em conta a maturidade dos alunos, a complexidade dos elementos considerados, o tempo disponível para a disciplina e o objetivo em si (discussão e/ ou implementação da solução). Nesse sentido, mostra-se que a literatura não é convergente em relação aos aspectos estruturais e a taxonomia. É fundamental a discussão sobre a implantação de cada abordagem, de modo a nortear a decisão de quando é mais eficaz utilizar o caso de ensino ou a aprendizagem centrada em projetos e baseada em problemas para atender os objetivos educacionais de um curso de controle gerencial.

Notou-se que, quando um problema é utilizado no processo de ensino e aprendizagem para sintetizar o conhecimento prévio aprendido e para desenvolver competências como o pensamento crítico, o trabalho em equipe, a comunicação, a resolução de problemas, as habilidades de pesquisa, pode-se utilizar como abordagem de ensino o Problem-based Learning (One-day One-problem, Case-based Learning ou Project-based Learning). Porém faz-se necessário observar o ambiente de aprendizagem, ou seja, a forma como será operacionalizado o PBL e os objetivos educacionais a serem obtidos, pois a complexidade do problema impacta as opções, bem como o contexto, que se mostra fundamental e deve fazer sentido para os participantes como parte da sua realidade.

Sugere-se que futuros estudos investiguem os benefícios e as restrições das três abordagens aqui apresentadas no que concerne ao emprego do PBL no ensino de contabilidade, bem como apresentem os reflexos de cada abordagem no aprendizado das competências do contador e na integração da pesquisa, da teoria e do mercado de trabalho no cenário acadêmico.

\section{Referências Bibliográficas}

ARAÚJO, Adriana Maria Procópio de; FREGONESI, M. S. F. A.; SOARES, M. A.; SLOMSKI, V. G. "Aplicação do Método Problem-based Learning (PBL) no Curso de Especialização em Controladoria e Finanças". In: CONGRESSO INTERNACIONAL PBL, São Paulo, 2010. 
ARAÚJO, Ulisses Ferreira de \& ARANTES, Valéria Amorim. "Comunidade, Conhecimento e Resolução de Problemas: o Projeto Acadêmico da USP Leste". In: ARAÚJO, Ulisses F. \& SASTRE, Genoveva (orgs.). Aprendizagem Baseada em Problemas no Ensino Superior. São Paulo: Summus, 2009, pp. 101-122.

BARROWS, Howard S. "A Taxonomy of Problem-Based Learning Methods". Medical Education, vol. 20, n. 6, 1986, pp. 481-486.

BENJAMINJUNIOR, Valdomiro \& CASA NOVA, S. P. C. "Teoria da Complexidade e Contabilidade: Estudo da Utilização da Aprendizagem Baseada em Problemas como Abordagem Complexa no Ensino de Contabilidade". In: $12^{\circ}$ CONGRESSO USP DE CONTROLADORIA E CONTABILIDADE, São Paulo, 2012.

COUGHLAN, Paul \& COUGHLAN, D. "Action Research: Action Research for Operations Management". International Fournal of Operations \& Production Management, vol. 22, n. 2, 2002, pp. 220-240.

DECKER, Isonir da Rosa \& BOUHUIJS, P. A. J. "Aprendizagem Baseada em Problemas e Metodologia da Problematização: Identificando e Analisando Continuidades e Descontinuidades nos Processos de Ensino-Aprendizagem". In: ARAÚJO, Ulisses F. \& SASTRE, Genoveva (orgs.). Aprendizagem Baseada em Problemas no Ensino Superior. São Paulo: Summus, 2009, pp. 177-204.

ENEMARK, Stig \& KJAERSDAM, F. "A ABP na Teoria e na Prática: a Experiência de Aalborg na Inovação do Projeto no Ensino Universitário". In: ARAÚJO, Ulisses F. \& SASTRE, Genoveva (orgs.). Aprendizagem Baseada em Problemas no Ensino Superior. São Paulo: Summus, 2009, pp. 17-42.

ESCRIVÃO FILHO, Edmundo \& RIBEIRO, Luis Roberto de Camargo. "Inovando no Ensino de Administração: uma Experiência com a Aprendizagem Baseada em Problemas (PBL)". Cadernos EBAPE. BR, Rio de Janeiro, vol. 6, número especial, ago. 2008, pp. 1-9.

FREZATTI, Fábio \& SILVA, S. C. "Prática Versus Incerteza: como Gerenciar o Aluno nessa Tensão na Implementação de Disciplina sob o Prisma do Método PBL?". Revista Universo Contábil, vol. 10, n. 1, 2014, pp. 28-46.

FREZATTI, Fábio; BORINELLI, M. L.; MARTINS, D. B.; ESPEJO, M. M. S. B. “'Análise do Desempenho de Alunos na Perspectiva do CHA em Disciplina Utilizando PBL: o Que Significa a Síntese?". Revista de Contabilidade e Organizações, vol. 10, n. 26, 2016, pp. 3-19.

HMELO-SILVER, Cindy E. "Problem-based Learning: What and How do Students Learn?" Education Psychology Review, vol. 16, n. 3, set. 2004, pp. 235-266.
LARMER, John. "Project-Based Learning vs. Problem-Based Learning vs. X-BL". Buck Institute for Education (BIE), jan. 2014. Recuperado de $\langle$ http://www. edutopia.org/blog/pbl-vs-pbl-vs-xbl-john-larmer >, em 28 fev. de 2015.

MARTINS, Daiana Bragueto \& ESPEJO, M. M. S. B. . PBL no Ensino de Contabilidade: Guia Orientativo para Professores e Estudantes da Nova Geração. São Paulo: Atlas. 2015.

MARTINS, Daiana Bragueto; ESPEJO, Márcia Maria dos Santos ; FREZATTI, F. . "Problem-based Learning no Ensino de Contabilidade Gerencial: Relato de uma Experiência Brasileira". Revista de Educasão e Pesquisa em Contabilidade (REPeC), vol. 9, n. 4, 2015, pp. 430-452.

RODRIGUES, Edna de Almeida \& ARAÚJO, A. M. P. "O Ensino da Contabilidade: Aplicação do Método PBL nas Disciplinas de Contabilidade em uma Instituição de Ensino Superior Particular". Revista de Educação, Itatiba, vol. 10, n. 10, 2007, pp. 166-176.

SAVERY, John R. "Overview of Problem-based Learning: Definitions and Distinctions". Interdisciplinary Fournal of Problem-based Learning. vol. 1, n.1, 2006, pp. 9-20.

SIQUEIRA, José Ricardo Maia de; SIQUEIRA-BATISTA, Rodrigo; MORCH, Rafael Borges; SIQUEIRA-BATISTA, Rômulo. "Aprendizagem Baseada em Problemas: o Que os Médicos Podem Ensinar aos Contadores". Revista Contabilidade Vista \& Revista, vol. 20, n. 3, 2009, pp. 101-125.

SOCKALINGAM, Nachamma; MARTINS, D. B.; FREZATTI, F. . "Practical Issues in Implementing Problem-based Learning: an International Perspective". In: $8^{\circ}$ INTERNATIONAL CONGRESS PAN PBL, Concepción, Chile, 2014. [CD-ROM].

STAKE, Robert E. The Art of Case Study Research. New York: Sage Publication, 1995.

WIEK, Amim; XIONG, A.; BRUNDIERS, K.; LEEUW, S. van der. "Integrating Problem and Project-based Learning into Sustainability Programs: A Case Study on the School of Sustainability at Arizona State University". International fournal of Sustainability in Higher Education, vol. 15, n. 4, 2014, pp. 431-449.

WOOD, Diana F. "ABC of Learning and Teaching in Medicine: Problem-based Learning". British Medical Fournal (BMJ), vol. 326, n. 7384, 2003, pp. 328-330.

WOODS, Donald R. "Problem-oriented Learning, Problem-based Learning, Problem-based Synthesis, Process Oriented Guided Inquiry Learning, Peer-led Team Learning, Model-eliciting Activities, and Project-based Learning: What Is Best for You?" Industrial \& Engineering Chemistry Research, vol. 53, n. 13, 2014, pp. 5337-5354. 